\title{
Are We Running Out of Truck Drivers? ${ }^{1}$
}

\section{Richard Beilock ${ }^{2}$}

\section{Introduction}

Florida is almost totally dependent upon trucking for interstate shipments of its agricultural products, as well as for receiving many of the inputs for its industries and consumers. Since at least the early 1980s, there have been growing concerns over the ability of the U.S. labor force to supply drivers. If there is a persistent and growing shortfall in the supply of drivers, costs to Florida's industries (agricultural and non-agricultural) and consumers will rise. Concerns about a driver shortage are primarily based on four factors:

1. Deregulation of the motor carrier industry (usually dated from 1980) is credited with accelerating industry growth, including the demand for drivers. At the same time, some claim that deregulation has resulted in reduced compensation and worsened working conditions (Belzer, 2000).

2. The U.S. population is aging. In 1994, the median age was 34 . Using the U.S. Census' middle-series projections, the median age is expected to increase to 39.1 years by 2035 (Day, 2002). This has potentially important implications for driving, considering the physical demands of this occupation.
3. The overall growth of the labor force is slowing (Figure 1).

4. Since the early 1980 s, there has been a general tightening of labor markets, with increased opportunities in higher paying, technical occupations.

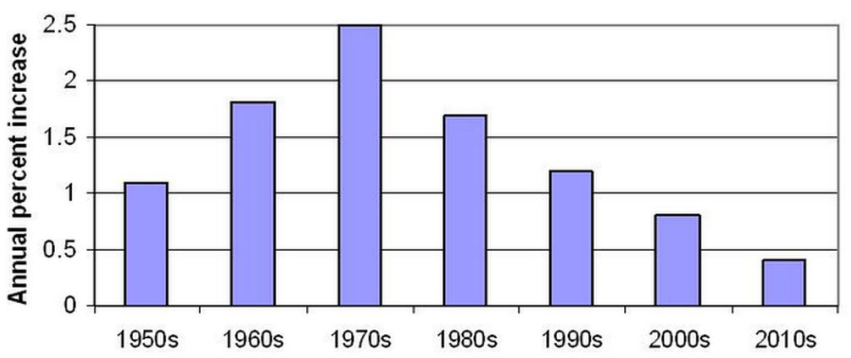

Figure 1. Annual increase in US civilian labor: 1950s-2010s.

During the 15 years preceding deregulation (i.e., 1965-1980), the number of trucking and courier service workers [Standard Industrial Classification (SIC) 421 ] in the United States increased by $31 \%$, while the entire labor force increased by $43 \%$. In sharp contrast, during the 15 years following deregulation (i.e., 1980-1995), the number of trucking and courier service workers increased almost twice as rapidly as the overall labor force (43\% versus $23.5 \%)$.

1. This is EDIS document, FE539, a publication of the Department of Food and Resource Economics, Florida Cooperative Extension Service, Institute of Food and Agricultural Sciences, University of Florida, Gainesville, FL. Published March 2005. Please visit the EDIS website at http://edis.ifas.ufl.edu.

2. Richard Beilock, Professor, Department of Food and Resource Economics, Florida Cooperative Extension Service, Institute of Food and Agricultural Sciences, University of Florida, Gainesville, FL. 
Many associated with the industry worry about these trends and some assert that driver supply already is critically short, particularly among non-union carriers.

In this report, the characteristics and opinions of long-haul refrigerated-truck drivers are examined to discern if and to what extent driver supply is eroding and if there are indications of worsening compensation and working conditions since deregulation. The information is based on a 2001/2 survey of over 1,600 long-distance truck drivers (Appendix; Beilock, 2004). It will be shown that, as with any labor market, problems do exist and some workers are dissatisfied. But overall, the results reveal high levels of satisfaction with and commitment to driving, including perceptions that compensation levels are satisfactory.

\section{Driver's Age}

If working conditions and pay have been deteriorating in trucking over the past 20 years, it might be expected that drivers would tend to be older, on average, than the labor force as a whole. This follows because younger individuals would have greater incentives than would their older counterparts to switch to better occupations. Moreover, as conditions in trucking deteriorate (relative to available alternatives), fewer new entrants into the labor force would choose driving as an occupation.

The average age of drivers in the survey was 44.4. To compare this with the U.S. labor force, data was used from the U.S. Bureau of Labor Statistics, or BLS (Fullerton, 1999). BLS includes workers as young as 16 . To be comparable with the trucking labor force, it was necessary to remove those under the age of 21 , who would be too young to acquire a Commercial Driver's License, or CDL (for the purpose of this study, 20-year-olds were assumed to equal $20 \%$ of the $20-24$ age category). With this modification, the average age of U.S. labor force participants in 1998 (the most recent year reported) was 40.5 (average age was calculated by dropping those under 20, using age category midpoint as the age of everyone in each age category, and assuming age 75 for those in the 75 -and-over age category). One further modification seemed in order. While the oldest driver in the sample indicated that he was 78 years of age, there were very few drivers older than 74. Given the requirements of this occupation, it seems likely that most individuals would be physically unable to continue driving into their late 70 s. For that reason, the BLS data were further modified to eliminate the oldest category ( 75 and older). The impact of this modification was minimal, resulting in an average age of 40.2 (note: eliminating those age 65-and-older only lowered the average age to 39.5 ).

The 4.2-year difference between the average ages of those in the truck driver sample and the U.S. labor force (i.e., $44.4-40.2=4.2$ ), while not necessarily alarming, is sizeable enough to question whether some who in past years would have become drivers are beginning to avoid the profession. Figure 2 illustrates the age distributions of those in the driver sample and the U.S. labor force. The main difference in the age distribution is the much smaller percentage of drivers who are 21 to 24 years of age, compared with the labor force as a whole, $2.4 \%$ versus $11.2 \%$, respectively. This is the principle cause of the difference in average age between truck drivers and the overall labor force. This could be due to one or more of the following:

1. Eroding conditions in trucking, relative to other professions, are discouraging those entering the labor force from becoming drivers.

2. Due to CDL age restrictions, new drivers are entering later than previously.

3. Entrants into driving always tended to be older than for the population as a whole.

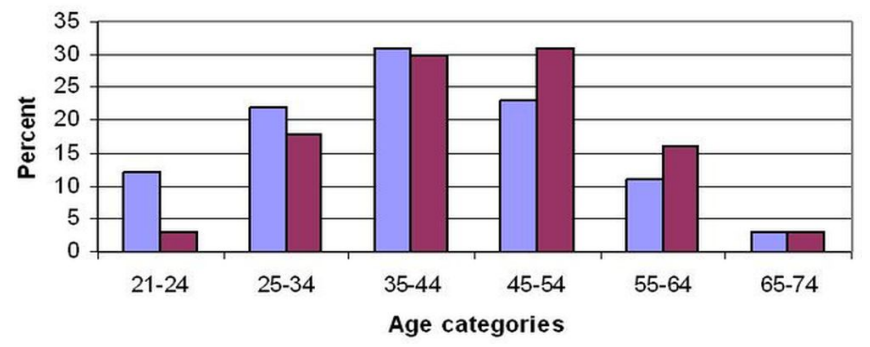

Figure 2. Age distributions of truck drivers and US labor force.

Certainly, because of the CDL age requirement, it would be expected that a smaller percentage of 
drivers would be in the 21-to-24 age category than would be in the entire labor force, but the extent of the difference suggests other reasons (i.e., eroding conditions and/or traditionally late entry). To gain some insight into trends in the ages of entrants into the driving profession, median entrant ages into driving (calculated as a driver's current age minus the number of years driver reported having been in the profession) were calculated by current driver age groups (Figure 3).

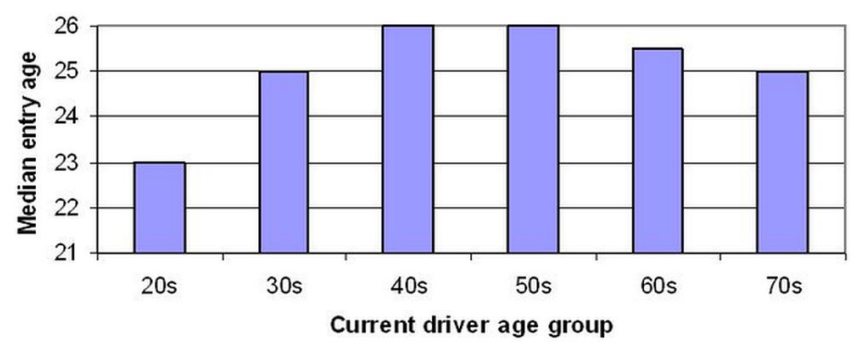

Figure 3. Median entry age of drivers.

The results suggest that late entry into driving is not a recent phenomenon. For drivers currently aged 30 and older, the median age of entry is 25 . So, regardless of current age, half the drivers first entered the profession when they were in their mid-20s or older. This result may, in part, be an artifact of the rapid growth of the profession since deregulation. For example, between 1965 and 1980, the number of production workers in trucking increased at an average annual rate of $2.1 \%$, compared with $3.7 \%$ between 1980 and 1995 (Belzer, 2002, p. 92). If unusually large numbers of older workers had entered in recent years, median ages would have been elevated. However, it seems unlikely that this alone would have generated the essentially flat median ages across all current driver age groups. Even if median entry ages are high because of recent entry of older workers, this could portend a good, even improving, labor supply situation. After all, the entire labor force is aging (Fullerton, 1999). The extent of the rapid growth (effectively doubling) in older drivers since deregulation in 1980 demonstrates the profession's ability to draw from the most rapidly growing part of the labor force.

\section{Driver's Enjoyment of Driving}

Certainly long-distance driving, with its lengthy periods away from home and frequently irregular work hours, is not for everyone. But while some would view such conditions as burdensome, others would see it as offering freedom, adventure, and variety. As with any profession, individuals tend to self-select according to job characteristics they prefer. Nevertheless, if working conditions have eroded severely since deregulation, both absolutely and relative to alternative occupations, overall enjoyment levels would be expected to be low. However, when asked if they enjoyed being truck drivers, $85 \%$ of the drivers responded affirmatively.

If working conditions have eroded since deregulation, those driving during the pre-deregulation era might be less likely than more recent entrants to enjoy driving. There is some evidence that this is the case, though enjoyment levels are high across all cohort groups. Drivers were divided into those who entered the profession before 1980 and those who entered after 1989. Entrants during the 1980s were omitted because that decade, arguably, was a transition period. While including entrants during the 1980s in the post-deregulation group does not alter the direction of the results, the resulting pre- and post-deregulation differences do become smaller. Among all drivers in the survey, $81 \%$ of those who entered the profession prior to 1980 reported that they enjoy driving, compared to $88 \%$ of those who entered after 1989 (Figure 4).

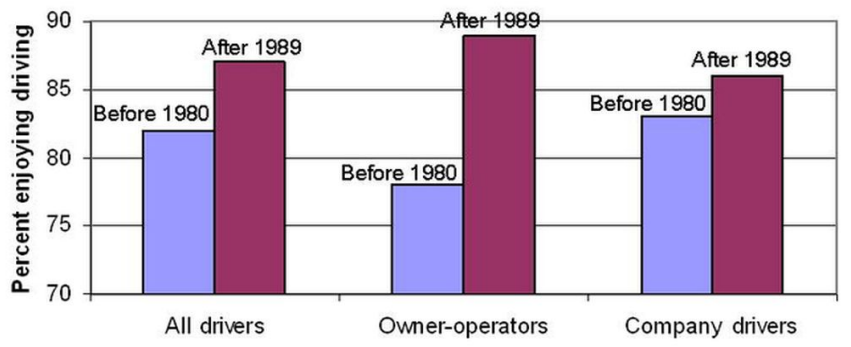

Figure 4. Driving enjoyment before and after deregulation.

This difference is largest among owner-operators (78\% and $89 \%$, respectively, for pre- and post-deregulation entrants). Among company drivers the difference is slight (83\% and $88 \%$, respectively). It should be noted that differences in driving enjoyment may, in part, be due to age. The average age of drivers who entered the profession before 1980 was 55 while the average age of those who entered after 1989 was 38. 


\section{Driver's Perception of Earnings}

Drivers were asked if they considered their earnings to be poor, average, or good. Asking drivers makes sense for at least three reasons. First, company drivers may be paid according to fairly complex formulae (e.g., so much per mile loaded, a different amount if empty, additional payments per pickup/drop, perhaps another rate for non-driving on-duty time, etc.). There may be periods of time when drivers can work as much as they want and other times when they are underemployed. If under lease, owner-operators will face similar payment systems and, if operating independently, their net earnings will depend upon a host of factors influencing their input costs (including brokerage fees) and ability to maintain high equipment utilization rates. Even if these formulae were known, it would be difficult, if not impossible, for a researcher to determine how they translate into effective earnings. But the drivers, of course, would know. Second, drivers would have reasonably good information about alternative earning opportunities.

That is, they would know the opportunity cost of their own labor. Third, drivers would know what they earned in the past and would be able to compare that with current earnings. Belzer describes wages to drivers as having dropped nearly $30 \%$ since deregulation (pp. 121-2) and being below the poverty level (p. 145). If this or anything close is the case, driver perceptions regarding their pay should be markedly negative.

Only $19 \%$ of all drivers characterized their pay as being poor, while nearly twice that amount said that earnings were good (see the first set of bars in Figure 5). Owner-operators were more likely than company drivers to report poor earnings, at $23 \%$ and $16 \%$, respectively (see the second and third set of bars in Figure 5). But for both groups, those perceiving earnings as good outnumbered those believing the opposite, and an overwhelming majority indicated that compensation was average or better. Regardless of changes between the pre- and post-deregulation eras, these results strongly suggest that compensation levels are generally perceived as being satisfactory or better.

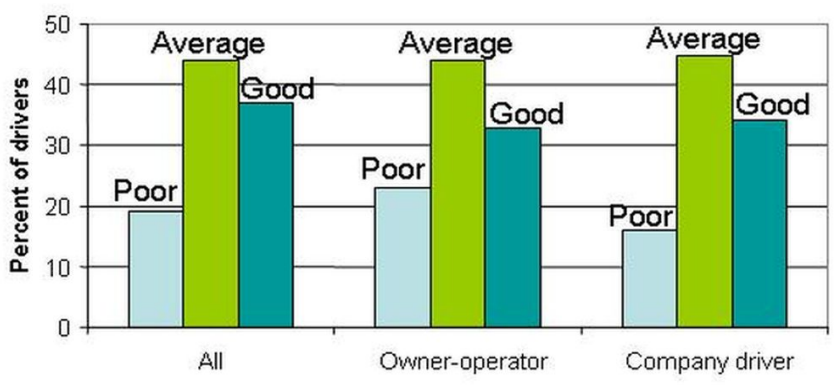

Figure 5. Earnings perception.

\section{Driver's Commitment to Driving}

To gauge commitment to their profession, respondents were asked if they believed they still would be driving in five years. Across the entire sample, $63 \%$ of the drivers responded positively, $10 \%$ were unsure, and $27 \%$ said no. Because of retirement plans and biological limitations, older drivers would be expected to be less likely to anticipate driving in five years. This is, indeed, the case. Up to age 50, approximately $70 \%$ of drivers believe they still will be driving in five years, with $10 \%$ unsure (Figure 6). After age 50,61\% of drivers believe they will still be driving in five years, with another $10 \%$ uncertain. Not surprisingly, much smaller percentages of drivers age 60 and older anticipate driving in five years. There are no significant differences, in these regards, between owner-operators and company drivers nor between those who entered the profession before or after deregulation (except, of course, higher percentages of pre-deregulation entrants are older drivers, and as such are less likely to anticipate driving in five years). As with perceptions regarding pay and driving enjoyment, a driver's intention of continuing in the profession suggests neither poor working conditions nor a crisis regarding the supply of drivers.

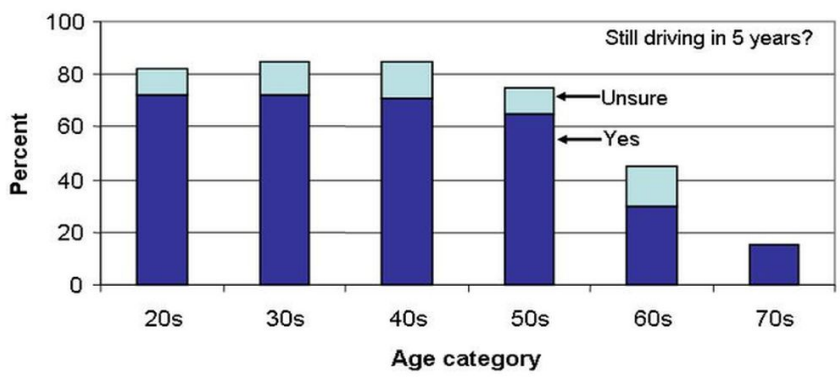

Figure 6. Expectation of driving in five years. 


\section{Driver's Current Employment}

Turnover rates in trucking are believed to be high and this is sometimes seen as symptomatic of both labor shortages and difficult working conditions. Comparison of years of tenure with current employer does, indeed, support the contention that turnover rates in trucking are considerably higher than for the labor force as a whole. BLS's Current Population Survey estimate of median years with current employer across all workers age 16 and older was 3.5 in February of 2000 (http://www.bls.gov/cps). They reported the same median as "motor vehicle operators"; however this category is not strictly comparable since it includes local truck drivers and operators of other types of motor vehicles. In the refrigerated-truck driver sample, the median years with current employer was 2 . In addition to being low, unlike the overall labor force, median years with current employer is not strongly related to age. In other words, unlike the labor force as a whole, truck drivers tend to move from employer to employer throughout their careers.

There are several reasons for questioning if these characteristics necessarily indicate problems in the labor market. While the median years of tenure with current employer are low for drivers relative to the labor force as a whole, it is comparable with those for several occupations. To illustrate this point, Figure 7 shows how BLS reported median years with current employer in February of 2000

(http://www.bls.gov/cps):

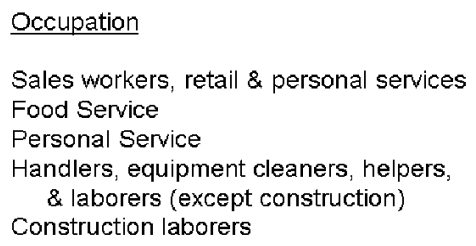

Figure 7. Median years with current employer.

These occupations share two characteristics with driving: relatively low skill levels and, in many cases, few opportunities for advancement. From the employer's standpoint, the cost of losing and replacing a lower-skilled employee is almost always less than for higher-skilled employees. This is particularly true as higher-skilled employees are more likely to have managerial responsibilities and/or detailed knowledge specific to the operation of that firm. So it is rational for employers to devote fewer resources to retaining lower- rather than higher-skilled employees. From the employee's standpoint, if there are few opportunities for advancement, there is little reason for loyalty to current employers, so switching jobs may be the best strategy for income enhancement.

\section{Summary}

The primary goals of this report were to reexamine whether driver working conditions and compensation have eroded since deregulation and whether this situation is contributing to driver shortages. Analyses of a survey of long-distance drivers, as well as secondary data (primarily from BLS), suggest that driver compensation levels are consistent with those for the economy as a whole, that drivers express high levels of satisfaction with driving and the payments they receive, and that the majority of drivers intend to remain in the profession at least over the next five years. Data regarding tenure with current employer indicate that turnover rates for drivers are higher than for those for the economy as a whole. But higher turnover rates would be expected in occupations, such as driving, which are semi-skilled and have few opportunities for advancement. Indeed, tenure with current employer is as short or even shorter in several other occupations that also tend to be lower-skilled and with fewer advancement opportunities.

In short, the supply of drivers may be tighter than in past decades, but it seems unlikely that there will be a severe shortage in the foreseeable future.

\section{References}

Ammah-Tagoe, R., and L. Randall. 2001. National Freight Data: Role in Strategic Transportation Decision-Making and Emerging Trends. Bureau of Transportation Statistics, U.S. Department of Transportation, Washington, D.C. Available online at http://www.reebie.com/TransearchSeminar/ SpeakerPresentations/ Final\%20Speaker\%20Presentations/A2/FAmmah.pdf. 
Beilock, R. 2004. Long Distance Refrigerated Trucking: A Florida Case Study. Report prepared for the Agricultural Marketing Service, United States Department of Agriculture, Washington, D.C.

Beilock, R., J. MacDonald, and N. Powers. 1988. An Analysis of Produce Transportation: A Florida Case Study. ERS/USDA Agricultural Economic Report 597, United States Department of Agriculture, Washington, D.C., 43 pp.

Belzer, M. 2000. Sweatshops on Wheels: Winners and Losers in Trucking Deregulation Oxford, UK: Oxford University Press.

Bureau of Labor Statistics. 2002. Working in the $21^{\text {st }}$ Century. Bureau of Labor Statistics Special Study, Washington D.C. Available online http://www.bls.gov/opub/home.htm.

Day, J. 2;002. National Population Projections. U.S. Census Report, Washington, D.C. Available online http://www.census.gov/population/www/pop-profile/ natproj.html.

Day, J., and E. Newburger. 2002. The Big Payoff: Educational Attainment and Synthetic Estimates of Work-Life Earnings. U.S. Department of Commerce, Bureau of the Census Special Study, Washington D.C.

Fullerton, H. 1999. Labor Force Projections to 2008: Steady Growth and Changing Composition. Monthly Labor Review (November):19-32.

Schleber, S. 2001. Labor Shortages and International Trade. Presentation to the Third Plenary of the Commission on Global Aging, Tokyo, Japan. Available online at http://www.csis.org/gai/tokyo/shieber/sld001/htm.

United State Department of Agriculture. Various years. Fresh Fruit and Vegetable Shipments by Commodities, States, and Months, annual volumes 1970-2002. Agricultural Marketing Service, United States Department of Agriculture, Washington D.C.

Winston, C. 1998. U.S. Industry Adjustment to Economic Deregulation. Journal of Economic Perspectives 12(3):89-110.

\section{Appendix: Data}

The 2001/2002 Driver Survey: This survey was conducted in November of 2001, and in January, March, and May of 2002. The survey sites included the Florida Agricultural Inspection Stations located on interstate highways U.S. I-10, U.S. I-75, and U.S. I-95. The drivers of 1,642 refrigerated tractor-trailers were interviewed as they exited the Florida Peninsula.

While the survey sites were all in Florida, the study has relevance for long-distance haulage throughout North America. The sample contained drivers from all 48 contiguous U.S. states and 8 Canadian provinces. These drivers were enroute to destinations in 46 states, the District of Columbia, and 7 Canadian provinces. Trip distances ranged from 100 to 3,347 miles, averaging 1,222 miles. 